\title{
Enhancing social capital for sustainable coastal development: Is satoumi the answer?
}

\author{
Yves Henocque *
}

IFREMER, 155 rue Jean-Jacques Rousseau, 92138 Issy les Moulineaux Cedex, France

*: Corresponding author : email address : $\underline{\text { Yves.henocque@ifremer.fr }}$

\begin{abstract}
:
Social capital constitutes the cultural component of modern societies. Building social capital has typically been seen as a task for "second generation" economic reform, but unlike economic policies and institutions, social capital is not created or shaped by public policy but is inherited throughout local communities successive generations. Enhancing social capital therefore is about promoting local knowledge deeply rooted into local communities' practices on land and at sea. In Japan, the culturally specific interaction of humans with nature has led to the emergence of specific socio-ecosystems called "satoyama" on the land side and "satoumi" on the coast and sea side. Here, characteristics of related local knowledge include information about consumed products like wild edible plants or seaweeds, and learning by doing practices like traditional rice cultivation or sea ranching. This knowledge has been developed over centuries and has been handed down from generation to generation. There are actually other types of satoyama and satoumi which have been flourishing around the world though the latter (satoumi) probably has no equivalent in other countries' coastal areas because of the unique Japanese fishing rights system. First largely ignored as a social capital, satoumi has emerged as a new concept only a few years ago. In the frame of the recently adopted national ocean policy such a social capital, like it may be found in other countries, should not be ignored when addressing integrated coastal zone management processes and tools for the sake of sustainable coastal development in Japan and elsewhere in the world.
\end{abstract}

Keywords : social capital ; Satoumi ; co-management ; coastal governance ; local involvement

\section{Introduction}

The management of natural resources is a paradigm in change from sustainable yield to sustainable ecosystems. This new paradigm is ecosystem management, and focuses on managing the ecosystem for the services it may provide, rather than for producing a single commodity or a limited number of commodities. However, our social system constraints our ability to manage the biosphere we are part of. Hence, ecosystem management is determined by human values and the capacity to translate scientific knowledge into governance and the management of social-ecological systems from an obviously „human-in-nature" perspective.

The underlying concept of governance is, though, blurred with the current debate on the role of political institutions in governance. Yet, while political institutions have been the dominant actors for 
some time, societal actors have, during recent decades, increasingly involved in governance. Reviewing different models of governance, Pierre and Peters (2005) concluded that the most effective forms of governance make use of both, social networks and a strong state, the former being at the core of the so-called ,social capital".

Social capital refers to "features of social organisation, such as trust, norms, and networks that can improve the efficiency of society by facilitating coordinated actions" (Putnam, 1993). The capacity to adapt to rapid and dramatic changes of governance largely depends on the balance between the stability provided by strong institutions on the one hand, and the capacity to experiment, innovate, and learn from changing circumstances, attributed to through well structured social networks (Duit and Galaz, 2008). The latter is considered an inherent part of a ,robust" governance of complex socialecological systems.

While social capital is a relatively new concept, its object, social networks, has a long history. As Putnam (1993) brilliantly demonstrated it in the case of Italy, "civic traditions may have 
powerful consequences for economic development and social welfare, as well as for institutional performance”, at municipal and regional level.

From an European perspective, the autonomy of the Prefectures in Japan can be compared to the one of the Italian Regions. Japan's civic traditions are deeply rooted in history, and expressed in the concept of satoyama and, more recently, the concept of satoumi. Although the cultures differ significantly, we approach the latter concept and practise (satoumi) as a form of adaptive co-management, i.e. "a process by which institutional arrangements and ecological knowledge are tested and revised in a dynamic, on-going, self-organized process of learning-by-doing” (Folke et al. 2002).

\section{Linking co-management and adaptive co-management}

In many countries, centralised management of coastal resources has not ensured sustainability. Centralised government agencies often lack the resources to enforce centrallevel management decisions, or to support local arrangements. Therefore, and often in the context of decentralisation, participatory and integrated management has succeeded in a better way. While various approaches have been used by different groups, management responsibility and/or authority that is shared between local communities and government or "co-management" is the key to any system improvement. More practically, co-management usually involves decentralised decision-making, providing an opportunity for partnership arrangements in which government, communities and other stakeholders share both the responsibility and the authority for decision-making and implementing agreed management plans (Arthur, 2005).

This process is less focused on the final outcome, but more on the processes and mechanisms that have produced it, and how they relate to participation and sustainability. Co-management works at the interface between the ecosystem and the human system, aiming at changes in the state of the first through behavioral changes of the second. It is therefore a dynamic process in which management planning is an iterative cycle. Adaptive management recognizes that all management is somewhat experimental, and that the results are not fully predictable, neither environmentally nor socially. Learning therefore is a continuous process, along the turning wheel of the project cycle.

Although much focus is on the local scale, adaptive co-management is a flexible system for environment and resource management that operates across multiple levels and with a range of local and non-local organisations. Many of the ideas and practises emerge from the field of common property (commons) and its implications for collaborative management (Ostrom, 2005), addressing issues such as (Armitage et al., 2007):

$>$ the evolutionary dimension of co-management, and the recognition that institution building, trust building, and social learning all require time and repeated rounds of learning-by-doing;

$>$ the realm of complex social-ecological systems, addressing issues of scale, multiple perspectives, uncertainty and non-linearity, self-organisation and emergence;

$>$ throughout up-scaling, the linkages of different levels of governance, from the community level to the regional and/or national levels;

$>$ the expansion of partnerships, recognizing that in most real-life co-management situations, there is a rich social capital, i.e. a rich web of social networks involving private and public actors; 
the recognition of a diversity of government agencies with different roles and relationships as a diversity of interests within communities themselves.

Figure 1 - The Adaptive Learning approach to co-management (Garaway, C.J. and Arthur, R.I. 2004)

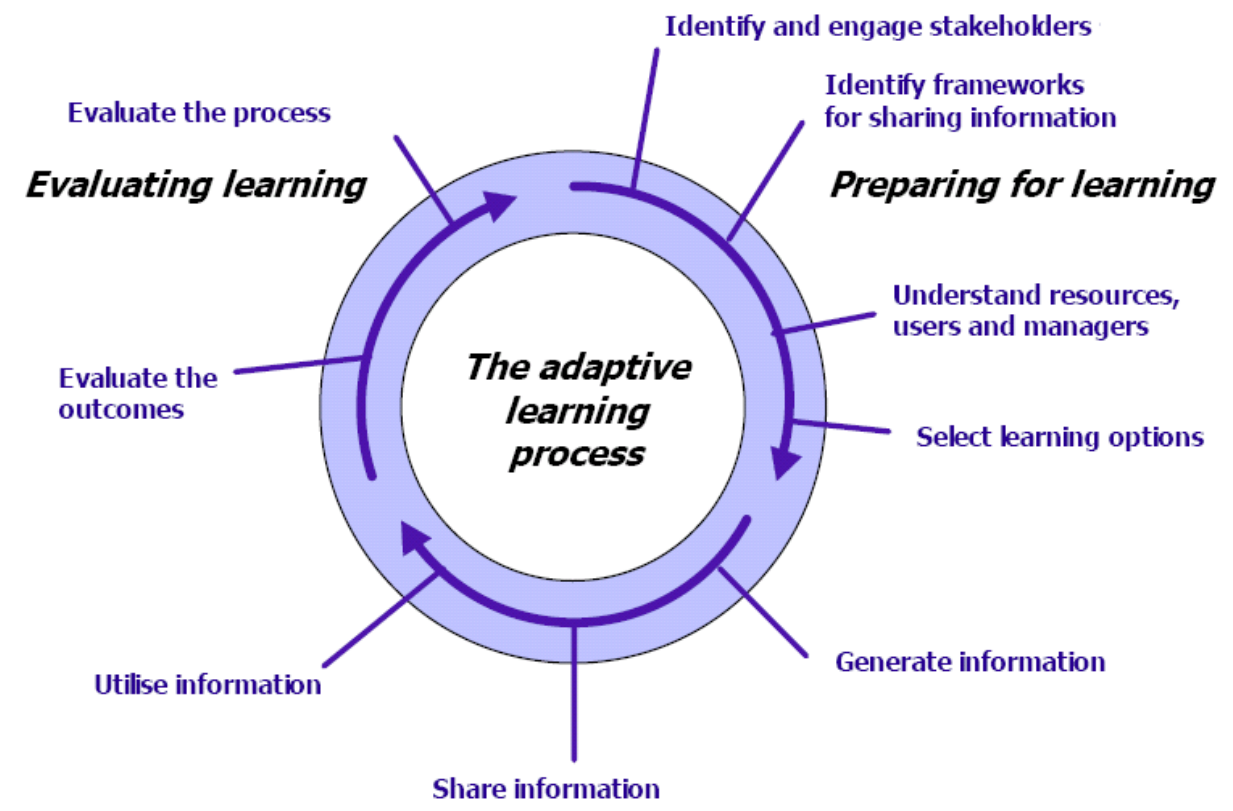

Learning

\section{A case study: dealing with social capital in Thailand}

CHARM (Coastal Habitats and Resources Management) was a five years project (2002-2007) jointly supported by the Royal Thai Government and the European Union. Under the Financing Agreement signed in 2001 between the European Community and the Kingdom of Thailand, CHARM specific objectives were to design and establish the coastal habitats comanagement framework and procedures in five Southern Thailand provinces that can serve as models to be replicated elsewhere in the country.

For the benefit of the project first beneficiaries, i.e. the coastal communities, CHARM has developed its approach around a number of co-management attributes including participation, partnership, capacity building, development of integrated approaches and methods, and learning and adaptation. It has shown that the future of coastal resources co-management for better coastal governance in Thailand is on one hand with skilled self-organized communitybased organizations and on the other hand strong, committed and enlightened local governments. It is from these two driving forces that a scheme or model of coastal comanagement and governance has been proposed throughout the following local government units and territories:

- The Tambon or sub-district (comparable to a municipality) through up-scaling conservation/occupational groups networking, strengthening of the local government, the Tambon Administration Organization (TAO), and institutional arrangement for communication and sharing of knowledge. 
- The Province through, at first, up-scaling specific issues related to conservation/occupational group networks like MCS (Monitoring Control Surveillance) for small-scale fisheries or CBT (Community-Based Tourism) amongst the villagers.

- The seascape units including large bays like Chalong Bay (Phuket), Phang Nga Bay, Trang Seas, and Ban Don Bay (Gulf of Thailand) where boundaries may be more easily related to ecosystem boundaries. Within these seascape territories CHARM has given the tools for dealing with smaller coastal management units in the frame of vulnerability indexing and mapping approach.

Improved coastal governance towards Integrated Coastal Management (ICM) depends on government, market and civil society mechanisms. At local level, it is conditioned by both skilled self-organized communities and strong committed local governments with negotiation and planning (Natural Resources Management Committee), learning (Learning centre) and financial (saving group) facilitating platforms. The awareness and contribution of the Education sector (schools) is considered as crucial for today and tomorrow. The upscaling process operates through the provincial governance level and volunteer organisations (VO) supported by coordinated Department provincial offices and NGO networks. As a driving force, the market mechanism calls for Public-Private partnership agreements. Knowledge centres (universities, research centres) got committed in the governance process through practicing useful knowledge transfers to users and decision-makers.

Figure 2 - CHARM adaptive co-management arrangement scheme (CHARM, 2007)

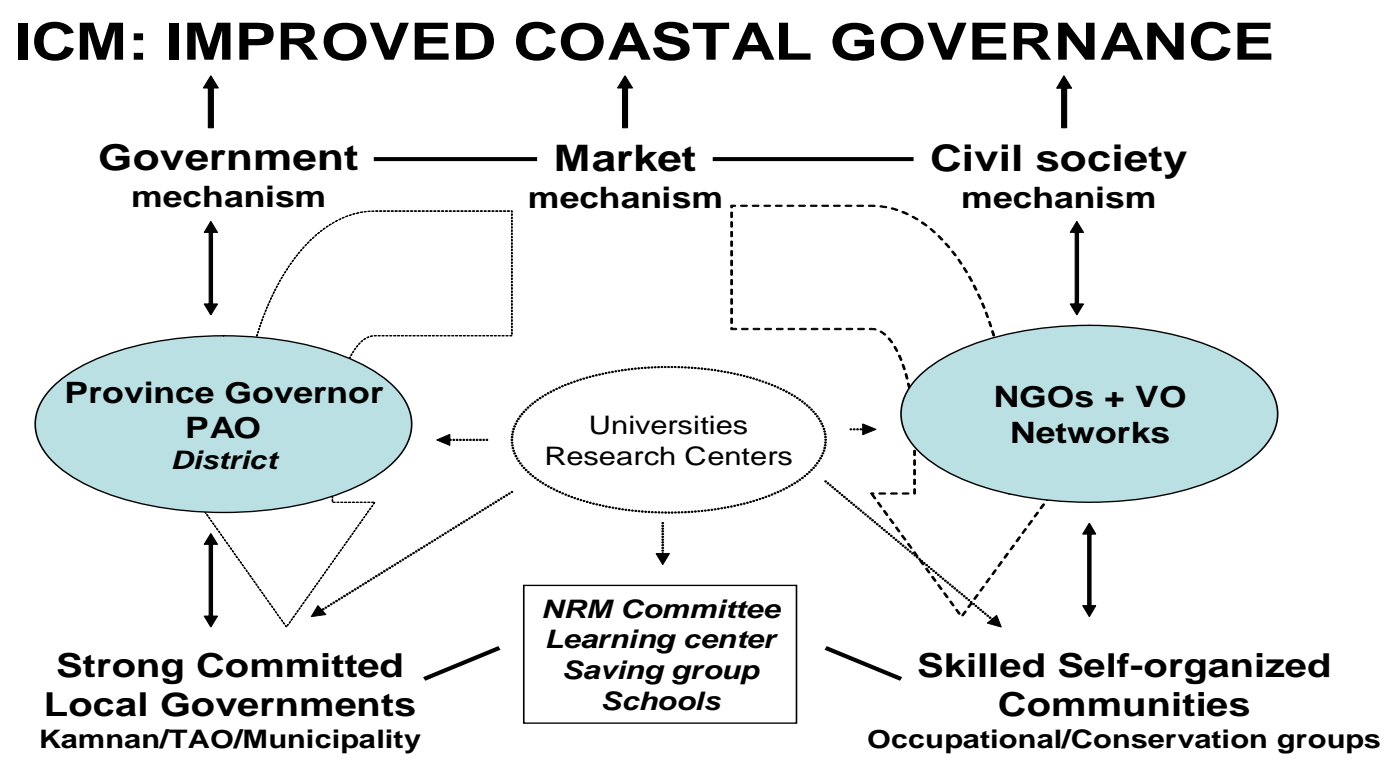

The preparation of a national coastal zone management policy, actively promoted during the last year of the project were based on these co-management initiatives at Tambon, Province and seascape levels. Some of the lessons learned may be commented as follows: 
Communities as complex systems embedded in larger systems - Communities, whatever they are, are not simple, they may be multi-level in structure and include competing groups and different interests. These complex communities are embedded in larger complex systems and global processes. The CHARM coastal governance vision (Figure 2) encompasses the nation as a whole and adopts the nested governance recognizing the dynamic interplay and the flow of information and resources circulating among and between layers of government, the economy and the social fabric of territories. For example, when constituency on communitybased tourism (CBT) is achieved in one Tambon with a strong leadership and technical support, it sparked the province of Surat Thani (Gulf of Thailand) to come up with a CBT development plan for the whole province.

Cross-scale governance - CHARM has been dealing with areas with quite different natural and administrative boundaries with more or less success in setting up co-management arrangements for coastal resources management planning. They are, 1) the village through conservation/occupational group strengthening and networking, 2) the Sub-district through the setting up of Natural Resources Management Committees, Information and Learning Centres, Saving groups and school network, 3) the Province through issue-related agreements (tourism, fisheries) and planning support and, 4) the seascape management units like Chalong Bay, Phang Nga Bay or Ban Don Bay leading the way towards a more ecosystem-based approach (Figure 3).

\section{Figure 3 - CHARM cross-scale governance}

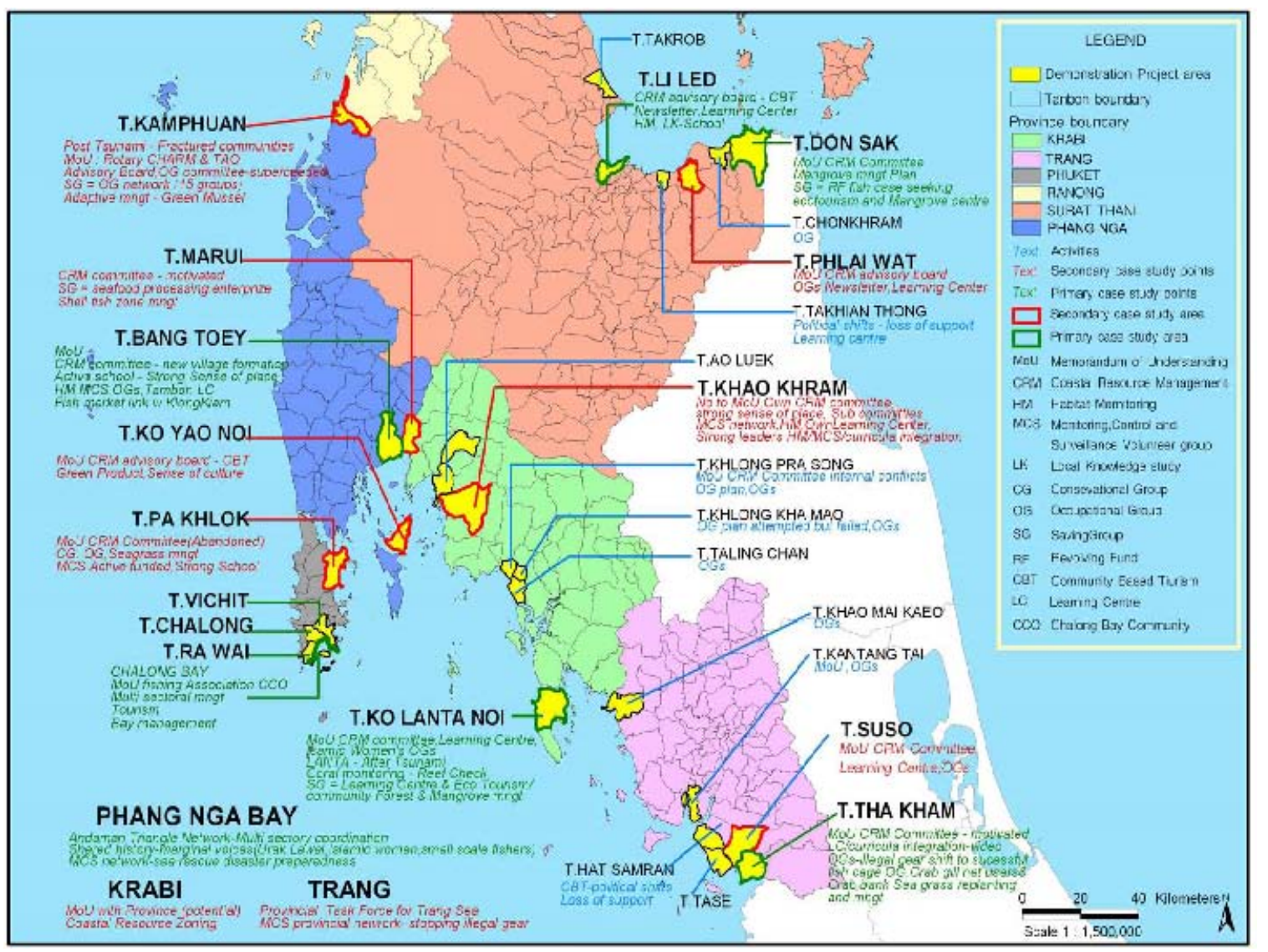

These co-management arrangements are in their infancy and have still to be strengthened keeping in mind that doing this, it is important to not only focus on individual project and 
products, but to remain strategic. With a vision (Figure 2) and a road map in mind, it may become easier to bringing practitioners from different projects and institutions to work closely together and to sketch out a common map where each party keeps its role and scale of intervention. At national level, an ICM National Dialogue has been set up toward that purpose.

Relating to each other's stories - Project leaders need to be able to find a way to relate to each other's experiences. Although each local or regional project has a different starting context and mode of implementation, each one is actually going through the same system of actors, institutions, processes and interactions, while they would be stronger in doing one thing instead of another. As a whole, they present comparative advantages that may strengthen the co-management and ICM process at local and national levels. Such was the goal of the ICM National Dialogue initiated in the last year of the project between PEMSEA ${ }^{1}$ and CHARM, respectively meaning the Chonburi Local Government Network in the upper part of the Gulf of Thailand, and the Phang Nga Bay/Ban Don Bay areas in the upper South of Thailand.

When the industrialized and therefore rich but environmentally threatened province of Chonburi comes up with a strong network of Municipalities, the Phang Nga Bay rural area can see skilled self-organised community groups developing through the Andaman Triangle Network (Phang Nga Bay as a seascape management unit) though still in need of local government support. Clearly, although in a different socio-economic context, the two initiatives have much to learn from each other while making other projects benefiting from their learning as shown below.

Figure 4 - The spreading of word mechanism

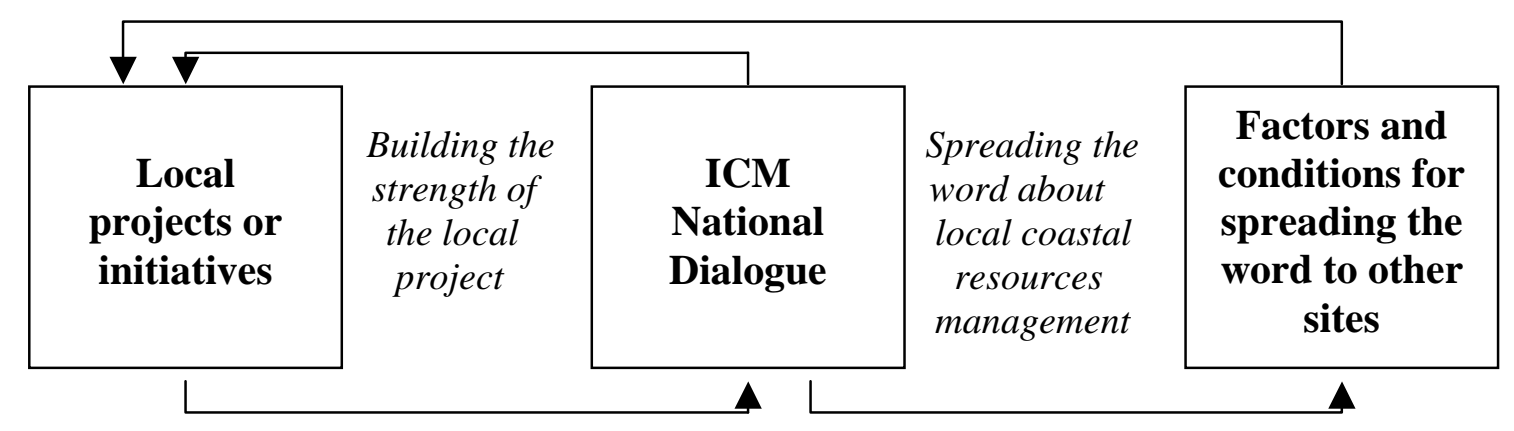

Strengthening occupational group networks - A strong focus on sustainable livelihood development facilitates marine conservation initiatives. Initial field projects focused on single village occupational group development. With the help of tools like the Fund Model Package (micro-credit mechanism), this has evolved over the years to multiple village occupational groups and more recently to occupational group networks legalized as community enterprises and community network enterprises under the support of the Agriculture extension Department. The formation of thematic occupational group networks may enable these groups to develop their own saving system, access funds from rural banks, increase marketing power and share transport costs. The intention of the strengthening strategy is to identify common problems, such as the lack of certain product development skills, appropriate packaging development or marketing research to develop links, and bring groups together that produce a similar product or face a similar problem. Groups are brought together through training workshops or study tours.

\footnotetext{
${ }^{1}$ PEMSEA: Partnerships in Environmental Management for the Seas of East Asia
} 
Engagement of the private sector - CHARM did work with the diving industry in Phang Nga Bay and some tourist operators but did not or could not include in its co-management activities the important private sector stakeholders that are the shrimp farmers and commercial fisheries though slightly in its last fisheries conflict resolution study. For some reasons, the Department of Fisheries made the choice to not overlap its specific policies in regard to these groups. Nevertheless, as shown in Figure 2, the private sector engagement is essential to any governance improvement and hence coastal resources co-management. Rather than considering the private sector as antagonist or at best mere sponsor, it is better to look at them as potential partners for the sustaining of activities.

Coastal and marine spatial planning at Provincial level - MOUs with Provincial Administration Organisation (PAO) as local government were to support activities implemented at local level. Vulnerability mapping in Phang Nga Bay and Ban Don Bay and their GIS have been transferred and incorporated, particularly in the case of Surat Thani and Krabi provinces. Zoning and planning activities have been encouraged with Phuket (Aquaculture) and Krabi (Coastal Resources Management master plan) provinces. CHARM has therefore contributed to some elements of future coastal and marine spatial planning at the scale of the province and coastal units like large bays (Ban Don Bay; Phang Nga Bay) using the political and legal momentum about improvement of provincial development planning and coordination of supporting budget.

Coordinated approach between government agencies - The Department of Fisheries and other government agencies provide their services as prescribed by the national policies, National Economic and Social Development Plans, pertinent laws, and their organizational mandates. Every fiscal year, they concoct their annual plans and submit them to the approving authorities and the Budget Bureau. Once these plans have been approved with the associated budget, they are expected to strictly follow the rules pertaining to fund disbursement and accounting to the designated beneficiaries. Placed in a high social hierarchy, it is unlikely that government officers will go beyond their prescribed functional territories. In a strategic move, it was recommended that change should be instilled where it is more navigable. In this regard, the two main levels of interventions are at the national and provincial level. At national level, through encouraging the debate or the consideration given by the Marine and Coastal Resources Management National Sub-Committee to the Green Paper and Policy Brief prepared by CHARM and submitted by the Department of Marine and Coastal Resources. At provincial level, with the reform of the Administration Act ( $7^{\text {th }}$ Amendment, 2007) and coming of new laws like the Marine and Coastal Resources Management Promotion Act, the provincial administration should become the center of spatial planning, hence getting much more clout in effectively coordinating sectoral activities through their respective government agencies.

Coastal management related research - There are many universities, institutes, and other organizations involved in coastal resources management related research in Thailand but the focus is more on the condition of coastal resources than on management itself. However, while working with them, it has been observed that some universities (e.g. Sukhotai Thammatirat University; Rajabhat Surat Thani University) are quite familiar in collaborating with NGOs or government agencies for the development of community-based coastal resources management. An informal network of CRM related research experts exists but has no institutional coordination that would give more coherence to research initiatives and would allow a more efficient transfer towards community organizations and local governments. On 
the model of the Thailand Research Fund, a Sea Grant Programme could facilitate in formulating a national vision, mission, and priorities for integrated coastal management research. Such a programme could be under the supervision of the Marine and Coastal Resources Management National Sub-Committee and managed by its Secretariat, the Department of Marine and Coastal Resources. It would be built on the principles of applied research, extension, communication, and education. Given the breadth of organizations involved in coastal resources management research, a Sea Grant programme should encourage research projects that involve researchers from several types of organizations (universities, government institutes, and NGOs).

NGO partnership - In the name of its partnership strategy considered as one of the major attributes of co-management, the CHARM project has permanently negotiated collaboration agreements with a number of NGOs, leading to the building up of a significant trust capital. The main observation is that most of them have an extended knowledge and experience in community-based management in their own field of intervention, but often show some weakness in dealing with institutions at the different level of governance, from Tambon to province territorial administrations. Beyond the community, they simply ignore or follow the traditional forms of leadership and participation, be there based on the principles of "virtue" or "power" and as adapted to fit existing political and bureaucratic institutions. Often, there is no coherent sense of where the pieces of their activities could fit into a broader national strategy. Moreover, with some exceptions like Save Andaman Network in the 2004 Tsunami aftermath, individual NGOs usually work in isolation from one another concentrating on implementing their projects in their "own” villages. As a result, it remains difficult to cutcross activities in a same village or Tambon between NGOs with which the CHARM project had specific agreements.

NGOs and more generally Voluntary Organizations represent a huge knowledgeable and skilled force in Thailand but have still to expand the scale of their programming and joining forces with others and with the government in order to achieve more comprehensive coverage of large populations. Creating the conditions of such a development through larger scale initiatives like the Andaman Triangle Network for Phang Nga Bay or the Trang Seas Coastal Resource Management Plan arrangement in Trang province became therefore an important project activity.

\section{Dealing with social capital in Japan}

Soon after the March 11 devastating earthquake and tsunami, one could read the following editorial title in a regional newspaper ${ }^{2}$ : "Japan earthquake underscores importance of social capital". It was said that "the conduct of the Japanese people after the most devastating disaster of the century showed the country's indestructible social capital”. As a matter of fact, if considering one of the typical indicator of structural social capital, there has been a growing density of association (NPOs and NGOs) since the 50's in Japan, and this increase is considered to be a response to emerging social demands and problems; the recognition of the limitations of public and private-sector enterprises; and an increase in government subcontracts (Inoguchi, 2002).

As stated in the Japan Satoyama Satoumi Assessment (2010), the origins of the latter (satoumi) "can be traced to the attempts of local communities to understand the relationship between human beings and the sea in the coastal areas of the Seto Inland Sea”, hence very

\footnotetext{
${ }^{2}$ Want China Times. Editorial of 28 March 2011
} 
much dealing with the available social capital since these initiatives, though recently encouraged by governmental programmes, are much dependent on "citizens, non-profit organisations (NPOs), and non-governmental organisations (NGOs)”.

Then, in most of the cases, the satoumi initiatives are related if not led by members of the Fishery Cooperative Association (FCA) and Fishery Management Organization (FMO), the functions of which facilitate the co-management regimes through the fishing rights "in response to declining harvest volume that threatened fishermen's economic well-being" (Uchida et Wilen, 2004).

The strong sense of environmental ownership developed by the fishermen thanks to their fishing rights has also been instrumental in national programmes like the Fisheries Agency's "Promoting the multifunctionality of fishing community and fisheries", mainly focused on marine ecological engineering to restore nursery habitats (e.g. seagrass beds) and strengthened the productivity of locally important species.

In Japan, fisheries organisations and their networks at provincial and regional levels make them an important component of social capital for the benefit of satoumi initiatives provided they open up to the other coastal and maritime activities and their various private sector organisations including the NPOs.

In short, though satoumi is conceptually linked to the centuries-old satoyama in a very specific cultural context, it may be usefully compared to the adaptive co-management approach that has been developed in many places around the world while it is particularly focused on "enhancing biological productivity and biodiversity through human intervention" (Japan Satoyama Satoumi Assessment, 2010).

\section{Discussion}

\section{Fishing rights and the role of fishing institutions}

In Japan, besides the rather recent involvement of environment-led NPOs, "common fishing right deeply connects with satoumi" making "the Japanese common fishing right institution a prototype of satoumi" (Hidaka, 2011).

Therefore, the discourse on satoumi cannot be disconnected from this unique and very original trait of fishing right in Japan where local communities and fishermen co-manage their coastal and marine resources through fisheries and/or aquaculture activities.

Successful community-based management or co-management, when it involves both local communities and local governments, have evolved in many parts of the world including in the United States (e.g. Maine lobster fishery).

If traditional socio-economic systems governed by customary practices and laws are allowed to determine fishery management plans and policies, some of the environmental damage of large-scale, industrial, mixed-stock fisheries can be avoided.

As already stated by a Japanese law specialist in 1997 in the case of the Seto Inland Sea (Nakayama, 1997), "with the issue of environmental protection becoming increasingly important to fisheries today, it is now necessary to aggressively position environmental protection laws within the legal system concerned with fisheries" and further, "because the protection of marine resources is an integral part of overall environmental conservation, and because it is a particularly vital issue for fisheries, fishery operators must be cast as major players in the environmental conservation struggle”. In other words, fishermen must realize that they are the main components in the marine resources use system, and that they therefore must actively participate in ecosystem-based fishery based on mutual agreements through existing or to-be-created governance forms and procedures. 
Because this issue concerns all the fisheries around the world and because of the unique system of fishing rights in Japan, this is a model that could be exported worldwide through the satoumi approach.

\section{Role and evolution of NPOs and NGOs}

Besides the fisheries, NPOs and NGOs represent another important social capital at the core of the satoumi approach. As observed by Korten (1990) when looking at the experience of NPOs/NGOs in development, there is a "definite pattern of evolution within the community away from traditional relief activities and toward greater involvement in catalyzing larger institutional and policy changes”. And later: “The pattern seemed to involve three identifiable stages or generations of strategic orientation, each moving further away from alleviating symptoms toward attacking ever more fundamental causes”. Since then and following NPOs/NGO leaders' recommendation, he decided to add a fourth generation to the scheme to make it complete (Annex 1).

In such a scheme, the involvement of Thai NGOs in the Indian Ocean 2004 Tsunami aftermath was typical of the first generation strategies, i.e. humanitarian assistance that relates directly to the individual or the family where the benefits delivered depend entirely on the funds, staff and administrative capability of the NGOs.

Although relief assistance has been soon associated with community organization, it has poorly or not at all addressed the strengthening of local governments to help those delivering better services to the local population. It corresponds to a community development strategy or "second generation" strategy through self-reliant local action focusing on occupational groups. Here, the NGO becomes more a mobilizer with combined funding coming from public and external donors, coming under pressure to develop a capacity in project management.

The current challenge is about the promotion of a third NGO generation strategy looking beyond the individual community and seeking changes in specific policies and institutions at local and provincial levels to provide negotiation forum and implementation units on a sustained basis. Yet, it remains to be seen to what extent the concerned NGOs may work with major national agencies to help them reorient their policies and working methods in ways that strengthen local control over natural resources.

This leads to the subject of partnerships where most of the cases involve co-management linkages and partnerships with communities and civil society actors on the one hand and governments bodies and agencies on the other. In the name of good governance, these partnerships should be extended to public/private partnerships, which still is much too rare in the area of coastal and marine resources management.

\section{Measuring outcomes}

Like adaptive co-management experiences in many parts of the world, satoumi in Japan is still in need of outcome measures or metrics. Performance evaluation is difficult, given the diversity of contextual factors in the various local initiatives. The methodological approach adopted in the national assessment (2010) focuses on changes in ecosystem services, which supposed a well-recognized and practical approach for defining the ecosystem services at stake and try to quantitatively or qualitatively give them a value or a grading, which is not an easy challenge.

Yet, each satoumi or adaptive co-management initiative should be considered as a sequence of project cycle generations, each of which links specific issues analysis and planning with the implementation of a course of action. Throughout successive project cycles, it is therefore important to analyse and comprehend the outcomes along a long-term trajectory that traces 
the advance to more sustainable forms of coastal development from local to regional scales (Figure 4).

Figure 5 - The orders of outcome (From Olsen, 2003)

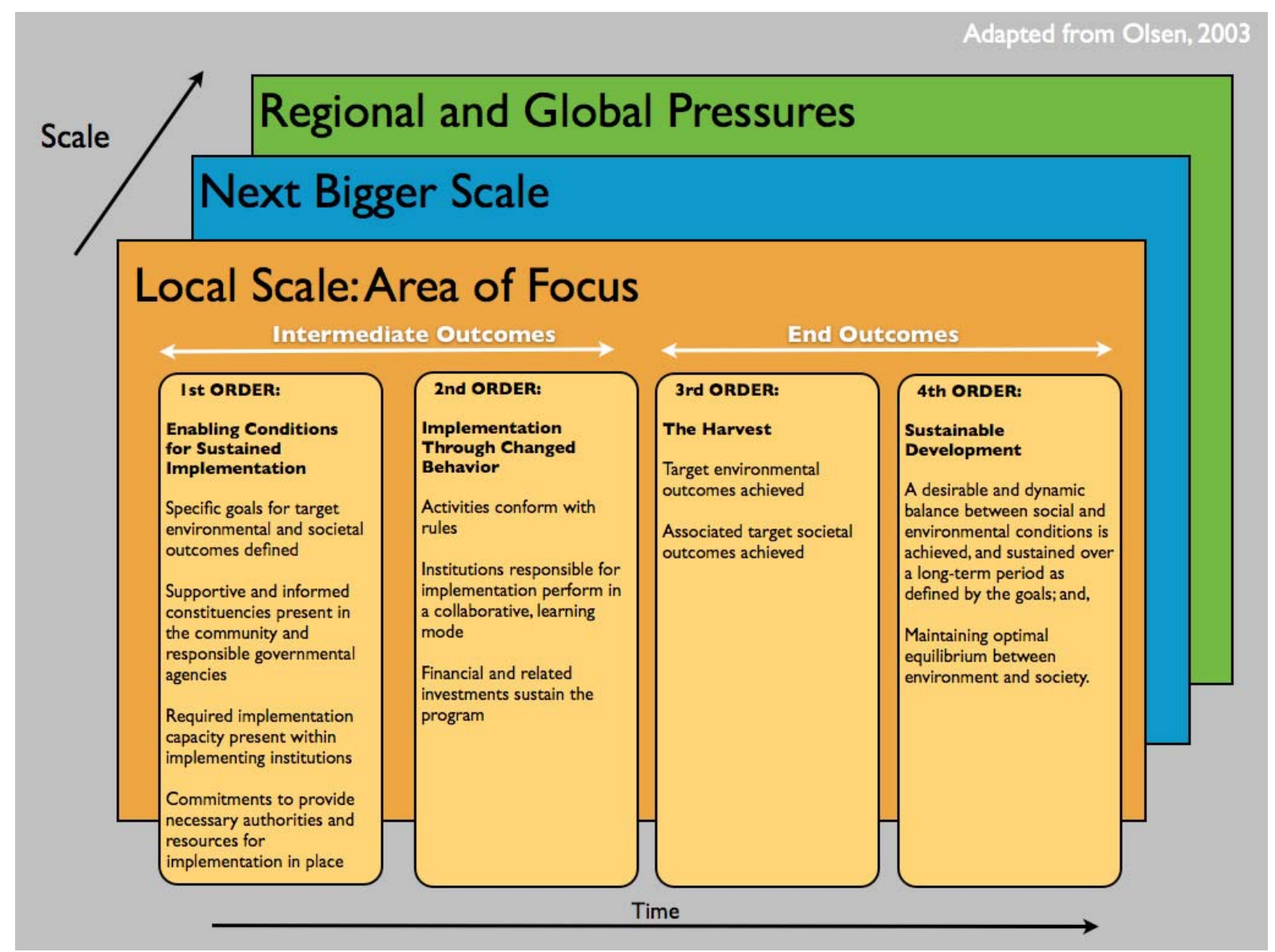

The first order or the enabling conditions are achieved when a project or a programme has succeeded in getting the constituencies actively supporting the co-management initiative, getting a formal agreement mandate along with the authorities concerned, getting the needed resources including sustained annual funding, getting a plan of action focused on specific and clear goals, and the institutional capacity necessary to implement the plan of action.

The second order is about changes in behaviour, be there individuals, interest groups or institutions in regard to,

- their capacity in negotiating and collective action (governance, research, education, private sector involvement...) for coherent planning from the water basin to the maritime basin ;

- their management practices (land use, shorefront development, port management, fishing/farming activities, maritime transport...);

- the level of investments attributed to co-management-related policies and plans (waste disposal, pollution reduction, shoreline protection works, port facilities, public access and information, protected areas, habitat restoration and fostering of the ecosystem productivity).

The third order of outcomes of a project or a programme may be considered as the return on investment for adequate and sustained specific achievements along the institutional and 
behavioural changes: water quality improves, fishing grounds getting more productive, income level is secured, and an adequate governance mechanism is in place for making these achievements sustainable and up-scalable.

Of course these achievements and changes are never the result of just one project but rather the result of multiple events and forces that coastal practitioners are to be able to play with. Any action should be driven throughout multiple objectives related to participation of individuals and interest groups, integration of the best reliable knowledge, taking into account the institutional mechanisms and the political context and opportunities.

Greater equity and social welfare (the social and economical spheres of sustainable development) should be among the major outcomes of adaptive co-management or satoumi endeavours. In that sense, it should strengthen the governance main features which are about participatory democracy (a booster of representative democracy) and accountability in regard to the implementation of policies, programmes and projects. Third Order outcomes fall into two broad categories: improvements in some coastal ecosystem functioning and services, and improvements in some societal qualities. Here, the satoyama/satoumi concept may be a powerful catchword for stakeholders' ownership in the sense that it links the drivers of change to the quality of ecosystem functions and services and finally to human well-being status, the very model of the Millennium Ecosystem Assessment although the latter did not say much about the key role of governance in dealing with the complexity of the model.

Actually, looking at experiences all over the world, far more effort has gone into developing, refining, and monitoring Third Order outcomes than either First (enabling conditions) or Second Order (changes in behaviour) outcomes, and this is generally well reflected in the design of coastal resource management initiatives, be there community-based management, adaptive co-management or the satoumi approach.

\section{Conclusion}

There is a long history of responses to the over-use and mis-use of goods and services provided by coastal ecosystems to human societies. For societies like island and archipelago states whose very survival has been dependent on effective coastal planning, engineering and the regulation of human activities that affect coastal ecosystem functions a rich history of adaptive co-management of coastal resources extends over many centuries. The use of social capital in coastal management as it has been exemplified in Japan throughout its satoumi approach, is a prerequisite of public participation and local involvement recognized as crucial components of integrated coastal management whatever the local and national context. If NGOs and community organizations, whatever their specific kind of approach, have always being playing a major role in coastal zone management initiatives around the world, it is important, beyond their specificities, to draw the common lessons allowing public participation to happen: political legitimacy through securing broad political support, processdriven approach in an inclusive, voluntary and culturally sensitive manner, empowering process of historically disadvantaged individuals, groups and communities, building partnerships to provide the basis upon which stakeholders can learn about and appreciate the interest of others, deepening public deliberation through alternative forums and participatory methodologies, and promoting innovation, reflection and feedback in response to changing circumstances and stakeholder interests. 


\begin{tabular}{|c|c|c|c|c|}
\hline \multicolumn{5}{|c|}{ Annex 1 - Strategies of Development-oriented NGOs (After Korten, 1990) } \\
\hline Problem definition & Shortage of basic needs & Local inertia & $\begin{array}{l}\text { Policy and institutional } \\
\text { constraints }\end{array}$ & $\begin{array}{c}\text { Inadequate mobilizing } \\
\text { vision }\end{array}$ \\
\hline Time frame & Immediate & Project life & 10 to 20 years & Indefinite future \\
\hline Chief actors & NGO & NGO + Community & $\begin{array}{l}\text { All relevant public and } \\
\text { private institutions }\end{array}$ & $\begin{array}{c}\text { Networks of People \& } \\
\text { Organizations }\end{array}$ \\
\hline NGO role & Doer & Mobilizer & Catalyst & Activist/Educator \\
\hline Management orientation & Logistics Management & Project Management & Strategic Management & $\begin{array}{c}\text { Coalescing self-managing } \\
\text { networks }\end{array}$ \\
\hline
\end{tabular}




\section{References}

Armitage D., F. Berkes, N. Doubleday. 2007. Adaptive co-management. UBCPress Ed. 344 pp.

Arthur R.I. 2005. Co-management: a synthesis of the lessons leraned from the DFID Fisheries Management Science Programme. MRAG Ltd., London.

CHARM 2007. CHARM completion report. November 2002 - November 2007. EuropeAid THA/RELEX/2000/0050

Duit A., V. Galaz. 2008. Governance and Complexity - Emerging Issues for Governance Theory. Governance: An International Journal of Policy, Administration, and Institutions, Vol.21, No.3, pp. 311-335.

Folke, C., S. Carpenter, T. Elmqvist, L. Gunderson, C.S. Holling, B. Walker, J. Bengtsson, et al. 2002. Resilience and sustainable development; Building adaptive capacity in a world of transformations. International Council for Science, ICSU Series on Science for Sustainable Development, no.3. http://www.sou.gov.se/mvb/pdf/resiliens.pdf

Garaway, C.J. and R.I. Arthur. 2004. Adaptive learning: a practical framework for the implementation of adaptive co-management- lessons from selected experiences in South and Southeast Asia. MRAG Ltd. London.

Hidaka, T. 2011. Rules and regulations supporting satoumi as social system. Satoumi Session, $9^{\text {th }}$ International Conference on the Environmental Management of Enclosed Coastal Seas (EMECS 9)

Inoguchi T. 2002. Broadening the basis of social capital in Japan. In: Putnam R.D., ed. Democracies in flux: the evolution of social capital in contemporary society. New York, Oxford University Press

Japan Satoyama Satoumi Assessment. 2010. Satoyama-Satoumi Ecosystems and Human Wellbeing: Socio-Ecological Production Landscapes of Japan. Summary for Decision Makers. United Nations University, Tokyo, Japan

Korten D. C. 1990. Getting to the $21^{\text {st }}$ Century- Voluntary action and the Global Agenda. Ed. Kumarian Press, Inc.

Nakayama, M. 1997. Legal systems and coastal management. In Sustainable Development in the Seto Inland Sea, Japan - From the Viewpoint of Fisheries. Eds. T Okaichi and T. Yanagi, pp. 189-214

Olsen S.B. 2003. Frameworks and indicators for assessing progress in integrated coastal management initiatives. Ocean \& Coastal Management 46 (3-4): 347-361

Pierre J., B.G. Peters. 2005. Governing complex societies. Trajectories and scenarios. Palgrave Macmillan Eds. 158 pp.

Putnam R.D. 1993. Making democracy work. Civic traditions in modern Italy. Princeton University Press. 258 pp.

Uchida H., J.E. Wilen. 2004. Japanese coastal fisheries management and institutional designs: a descriptive analysis. IIFET 2004 Japan Proceedings. 